\title{
The Clinically Significant Estimated Glomerular Filtration Rate for Hyperkalemia
}

\author{
Kenmei Takaichi ${ }^{1}$, Fumi Takemoto ${ }^{1}$, Yoshifumi Ubara ${ }^{1}$ and Yasumichi Mori ${ }^{2}$
}

\begin{abstract}
Objective Reduced glomerular filtration rate (GFR) is a risk factor of cardiovascular diseases. Accurate assessment of GFR together with early and appropriate treatment of chronic kidney disease (CKD) is important. Although the Japanese Society of Nephrology has recently announced two equations (equation 0.741 and equation 194) to estimate GFR for Japanese, the clinically significant estimated GFR (eGFR) in Japanese has not been identified. We examined the clinical significance of eGFR with regard hyperkalemia.

Methods A total of 9,196 patients who were examined and treated at the Toranomon Hospital between January and October 2005 were studied. Patients with a serum potassium level of $5 \mathrm{mEq} / \mathrm{L}$ or above or who were taking potassium adsorbent were classified as hyperkalemic. The effect of eGFR on the incidence of hyperkalemia was examined. The factors causing elevated serum potassium were analyzed after excluding the patients on potassium absorbent.

Results Multivariate analysis identified reduced eGFR, diabetes, male gender, aging, and use of reninangiotensin system inhibitors as the factors associated with an elevated serum potassium level. In an eGFRstratified analysis, each subgroup with eGFR below $50 \mathrm{~mL} / \mathrm{min} / 1.73 \mathrm{~m}^{2}$ when equation 0.741 was used, and eGFR below $60 \mathrm{~mL} / \mathrm{min} / 1.73 \mathrm{~m}^{2}$ when equation 194 was used had a significantly higher incidence of hyperkalemia compared with almost all of the subgroups with higher eGFR.

Conclusion From the viewpoint of the increase in incidence of hyperkalemia, using an eGFR below 50 $\mathrm{mL} / \mathrm{min} / 1.73 \mathrm{~m}^{2}$ as the cutoff has clinical significance when equation 0.741 is used and a cutoff at $60 \mathrm{~mL} /$ $\min / 1.73 \mathrm{~m}^{2}$ is appropriate when equation 194 is used.
\end{abstract}

Key words: eGFR, CKD, hyperkalemia, MDRD equation, diabetes, RAS inhibitors

(Inter Med 47: 1315-1323, 2008)

(DOI: 10.2169/internalmedicine.47.0944)

\section{Introduction}

A marked increase in end-stage renal disease (ESRD) has been recognized globally $(1,2)$. Furthermore, an association between reduced renal function and an increased risk of cardiovascular disease has been reported in the United States (3) and Japan (4). The important impact of the presence of renal disorder, especially reduced renal function, on organs other than the kidney, such as the cardiovascular system, is becoming evident.

In 2002, the US National Kidney Foundation approved a glomerular filtration rate (GFR) of $60 \mathrm{~mL} / \mathrm{min} / 1.73 \mathrm{~m}^{2}$ as the cutoff for an increased risk of cardiovascular disease (CVD) (3), and a staging system that defined chronic kidney disease (CKD) as a GFR below $60 \mathrm{~mL} / \mathrm{min} / 1.73 \mathrm{~m}^{2}$ was published (5). In Japan also, the Japanese Society of Nephrology published clinical practice guidelines in 2007, defining CKD as a GFR below $60 \mathrm{~mL} / \mathrm{min} / 1.73 \mathrm{~m}^{2}$ (6).

However, a study comparing the distribution of GFR in the Japanese and US populations showed that in general GFR is slightly lower in Japanese (7). Thus, the appropriateness of using the clinically significant level of GFR below $60 \mathrm{~mL} / \mathrm{min} / 1.73 \mathrm{~m}^{2}$ in Japan as in US and Europe remains unclear.

In the routine clinical setting, the serum creatinine level

${ }^{1}$ Kidney Center, Toranomon Hospital and Okinaka Memorial Institute for Medical Research, Tokyo and ${ }^{2}$ Division of Metabolism, Toranomon Hospital, Tokyo

Received for publication January 22, 2008; Accepted for publication April 12, 2008

Correspondence to Dr. Kenmei Takaichi, takaichi-tky@umin.ac.jp 
had been conventionally used as an indicator of renal function. However, it is well known that the serum creatinine level does not depend on renal function alone, but also changes according to physical attribute and other factors. Together with the diffusion of the concept of CKD, discussions based on estimated GFR have become widespread. The Modification of Diet in Renal Disease (MDRD) equation is a widely used method for estimating GFR, which is calculated based on age, gender and serum creatinine level. However, an estimated GFR equation modified for Japanese was not available until recently. In 2007, the Japanese Society of Nephrology published the GFR estimation equation for Japanese based on measured values from the Japanese population (6). In a previous study, we examined the factors affecting the serum potassium level using the serum creatinine level as an indicator of renal function, and reported that reduced renal function, diabetes, use of inhibitors of the renin-angiotensin system and old age are independent factors that increase the serum potassium level (8).

The purposes of the present study were to evaluate renal function using estimated GFR (eGFR) calculated from the equation modified for Japanese and to elucidate the factors affecting serum potassium level, and further to find the renal function level showing an increased incidence of hyperkalemia as well as the clinically significant eGFR level for hyperkalemia.

\section{Methods}

This study was approved by the Toranomon Hospital Institutional Review Board of Clinical Research and the requirement of informed consent from the patients was waived because of its retrospective design.

We retrospectively reviewed the records of all patients with clear records of prescribed drugs, who were treated at the Nephrology Department or Diabetes Department of the Toranomon Hospital between January and October 2005 as previously reported (8). After excluding patients on dialysis and patients on diuretics that lower serum potassium level, 9,196 patients were included in the study. First the relationship between renal function based on eGFR and the incidence of hyperkalemia was analyzed. Patients who had a serum potassium level of $5 \mathrm{mEq} / \mathrm{L}$ and above or who were using cation exchange resin were classified as hyperkalemic. An analysis of factors causing the increase in serum potassium level was conducted in 9,155 patients, after excluding those on potassium absorbent.

The factors investigated were age, gender, serum potassium level, serum creatinine level, casual blood glucose, fasting blood glucose and $\mathrm{HbA}_{\mathrm{lc}}$. Furthermore, the medications prescribed during the study period were also evaluated. When multiple serum level data were available for the same patient during the study period, the data obtained at the time of the highest serum potassium level for that patient were used for analysis. When examining the effect of medications, the medications prescribed during that time point were analyzed.

Estimated GFR was calculated using the equation reported in the clinical practice guidelines for diagnosis and treatment of chronic kidney disease (6) as follows [Here, this equation is termed "equation 0.741 ".]:

Male: eGFR $\left(\mathrm{mL} / \mathrm{min} / 1.73 \mathrm{~m}^{2}\right)=0.741 \times 175 \times \mathrm{Cr}^{-1.154} \times \mathrm{Age}^{-0.203}$

Female: eGFR $\left(\mathrm{mL} / \mathrm{min} / 1.73 \mathrm{~m}^{2}\right)=0.741 \times 175 \times \mathrm{Cr}^{-1.154} \mathrm{Age}^{-0.203} \times$ 0.742

The Japanese Society of Nephrology also introduced another equation (termed here "equation 194") to estimate GFR in the annual meeting in 2007 as follows:

Male: eGFR $\left(\mathrm{mL} / \mathrm{min} / 1.73 \mathrm{~m}^{2}\right)=194 \times \mathrm{Cr}^{-1.094} \times \mathrm{Age}^{-0.287}$

Female: eGFR $\left(\mathrm{mL} / \mathrm{min} / 1.73 \quad \mathrm{~m}^{2}\right)=194 \times \mathrm{Cr}^{-1.094} \times \mathrm{Age}^{-0.287} \times$ 0.739

The confirmation of the validity of equation 194 is now in process. Since both equations may be used in the future, we calculated eGFR with both equations.

To analyze the relationship between serum potassium level and renal function, patients were stratified according to eGFR ( $\mathrm{mL} / \mathrm{min} / 1.73 \mathrm{~m}^{2}$ ) as follows: below 10,10 or above but below 20, 20 or above but below 30,30 or above but below 40,40 or above but below 50,50 or above but below 60,60 or above but below 70, 70 or above but below 80, 80 or above but below 90, 90 or above but below 100, and 100 or above.

For the analysis of status of diabetes, a patient who had a casual blood glucose level of $200 \mathrm{mg} / \mathrm{dL}$ or above, a fasting blood glucose level of $126 \mathrm{mg} / \mathrm{dL}$ or above, or $\mathrm{HbA}_{1 \mathrm{C}} 6.5 \%$ or above during the study period was judged to be diabetic.

Data are presented in mean \pm standard error (SE) unless specified otherwise. Serum potassium levels were compared by analysis of variance. The incidence of hyperkalemia was compared using chi-squared test. Comparison of multiple variables was performed using Bonferroni method. The relationship between the serum potassium level and other factors was analyzed by multiple regression analysis. Correlation was considered significant at the 0.05 level (2-tailed). Data analyses were performed using SAS.

\section{Results}

The baseline characteristics of 9,196 patients are shown in Table 1. The mean age was $60.0 \pm 0.1$ years, $57.8 \%$ were males, and $39.5 \%$ were diabetic.

The relationship of the eGFR calculated with equation $0.741\left(\mathrm{eGFR}_{0.741}\right)$ and that calculated with equation 194 $\left(\mathrm{eGFR}_{194}\right)$ was examined. Although they were correlated very well, i.e., eGFR ${ }_{194}=1.0282 \times \mathrm{eGFR}_{0.741}+1.1112, \mathrm{R}^{2}=0.9906, \mathrm{p}<$ 0.001 , eGFR ${ }_{194}$ tended to be higher than $\mathrm{eGFR}_{0.741}$. We present the results using eGFR calculated with both equations.

The numbers of patients stratified by eGFR are shown in Fig. 1. The proportions of all patients with eGFR below 60 $\mathrm{mL} / \mathrm{min} / 1.73 \mathrm{~m}^{2}$ calculated with equation 0.741 and equation 194 were $28.9 \%$ and $24.3 \%$, comprising $14.2 \%$ and $11.9 \%$ with eGFR 50 or above but below $60 \mathrm{~mL} / \mathrm{min} / 1.73 \mathrm{~m}^{2}$, $7.0 \%$ and $5.8 \%$ with eGFR 40 or above but below $50 \mathrm{~mL} /$ 
Table 1. Baseline Characteristics of Patients

\begin{tabular}{ll}
\hline Number & 9196 \\
Age, years (range) & $60.0 \pm 0.1$ a) $(14-102)$ \\
Male / female, number (\%) & $5316(57.8) / 3880(42.2)$ \\
Diabetes, number (\%) & $3629(39.5)$ \\
Estimated GFR, $\mathrm{mL} / \mathrm{min} / 1.73 \mathrm{~m}^{2}$ & $69.21 \pm 0.22^{\mathrm{a})}$ \\
Serum creatinine, $\mathrm{mg} / \mathrm{dL}$ & $0.88 \pm 0.01$ a) \\
Serum potassium, $\mathrm{mEq} / \mathrm{L}$ & $4.47 \pm 0.004$ a) \\
Medications, number $(\%)$ & \\
$\quad$ Renin-angiotensin system inhibitors & $1161(12.6)$ \\
\hline a): mean + S.E.
\end{tabular}
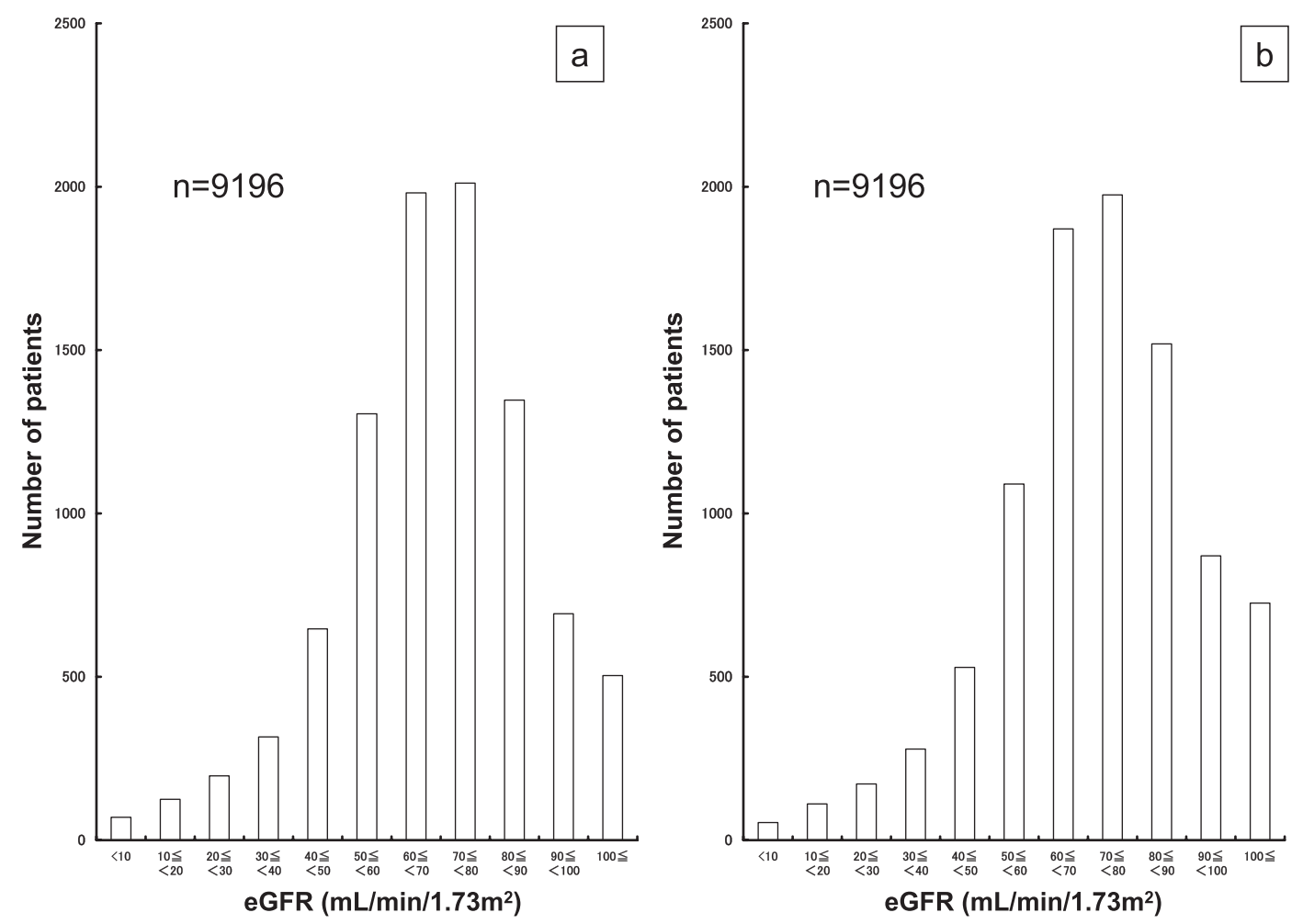

Figure 1. Number of patients stratified by estimated glomerular filtration rate (eGFR). a: eGFR was calculated using equation 0.741. b: eGFR was calculated using equation 194.

$\min / 1.73 \mathrm{~m}^{2}, 3.4 \%$ and $3.0 \%$ with eGFR 30 or above but below $40 \mathrm{~mL} / \mathrm{min} / 1.73 \mathrm{~m}^{2}$, and $4.3 \%$ and $3.7 \%$ with eGFR below $30 \mathrm{~mL} / \mathrm{min} / 1.73 \mathrm{~m}^{2}$, respectively.

In order to compare with our previous data (8), the effects of various factors on serum potassium level were analyzed for 9,155 patients, excluding those who were using cation exchange resin. In this patient group, the mean age was $60.0 \pm 0.1$ years, $57.7 \%$ were males, and $39.5 \%$ were diabetic. The mean serum potassium levels of patients stratified by eGFR are shown in Fig. 2. The serum potassium level increased with a decrease in estimated GFR.

The correlation between age and serum potassium level is shown in Fig. 3. A significant $(p<0.001)$ increase in serum potassium level with age increase was observed. Regarding the relationship between gender and serum potassium level, the mean level was $4.52 \pm 0.005 \mathrm{mEq} / \mathrm{L}$ in males and $4.40 \pm$ $0.006 \mathrm{mEq} / \mathrm{L}$ in females, and was significantly $(\mathrm{p}<0.001)$ higher in males.

The mean serum potassium level was $4.40 \pm 0.005 \mathrm{mEq} / \mathrm{L}$ in non-diabetic patients compared with $4.56 \pm 0.006 \mathrm{mEq} / \mathrm{L}$ in diabetic patients, and was significantly $(\mathrm{p}<0.001)$ elevated in diabetic patients. The mean serum potassium levels in patients stratified by eGFR and divided into diabetic and nondiabetic are shown in Fig. 4. In all groups with eGFR over $20 \mathrm{~mL} / \mathrm{min} / 1.73 \mathrm{~m}^{2}$, diabetes comorbidity was associated with significant increases in serum potassium level.

The relationship between the serum potassium level and inhibitors of the renin-angiotensin system (RAS inhibitors) that may cause elevation of serum potassium level was analyzed. Compared to the level of $4.45 \pm 0.004 \mathrm{mEq} / \mathrm{L}$ in the 

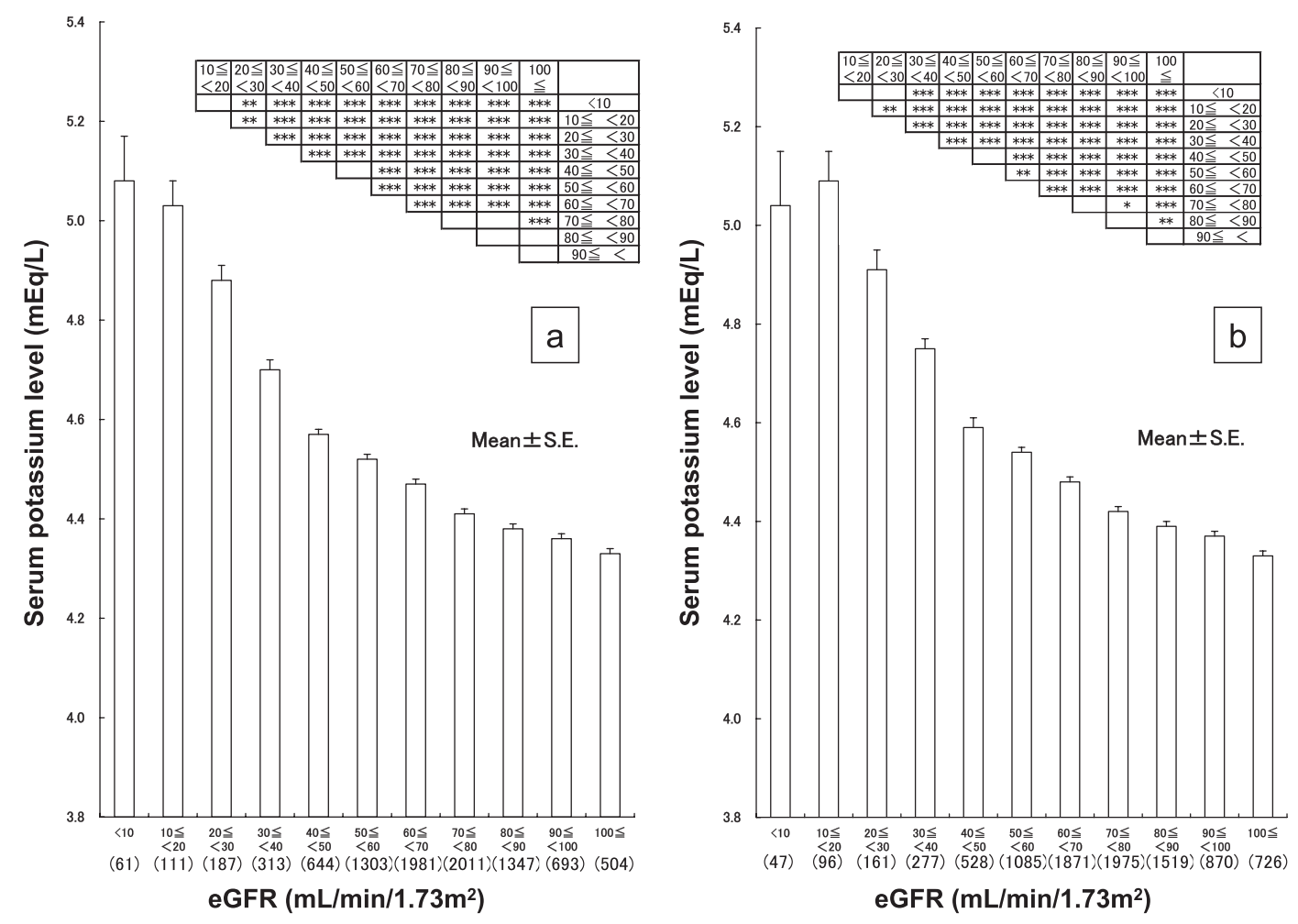

Figure 2. Serum potassium level stratified by estimated glomerular filtration rate (eGFR). a: eGFR was calculated using equation 0.741 . b: eGFR was calculated using equation 194. The number of the patients in each group is shown in parentheses.

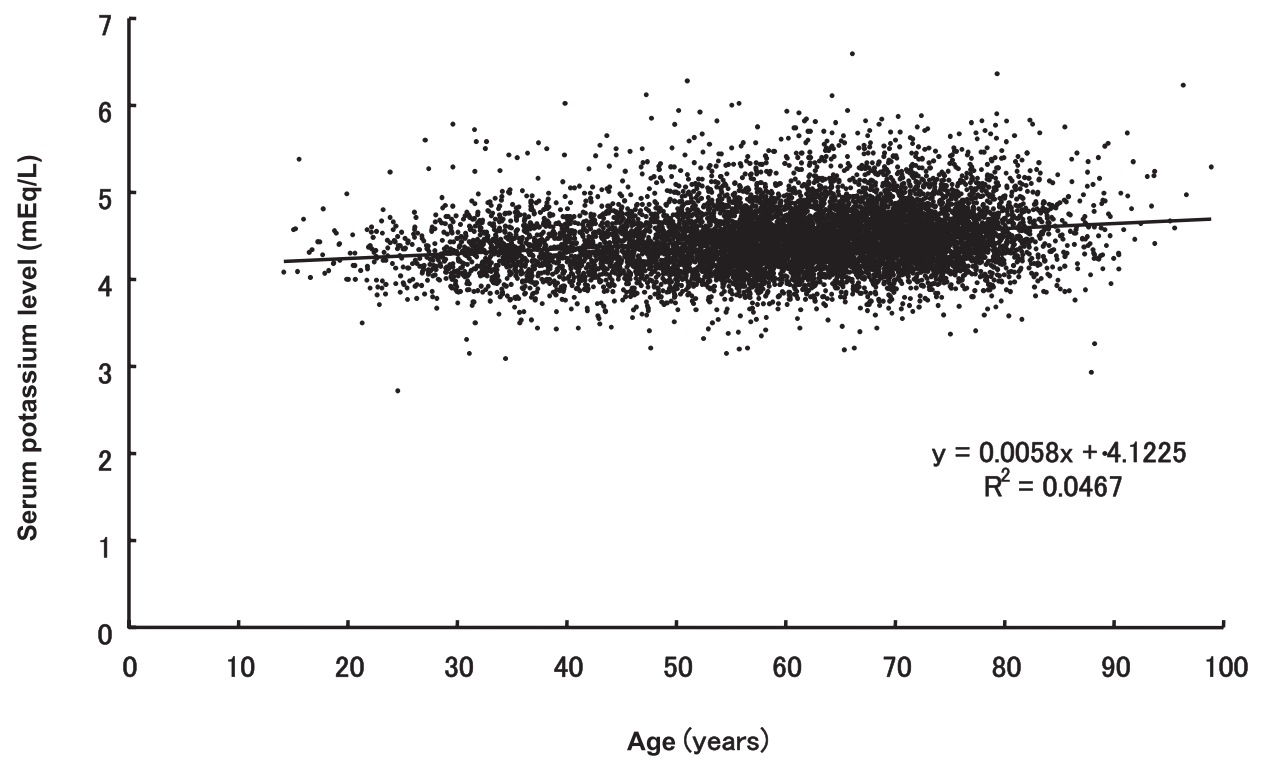

Figure 3. Correlation between serum potassium level and age.

group not prescribed RAS inhibitors, the mean serum potassium level was significantly $(\mathrm{p}<0.001)$ elevated in both the group prescribed angiotensin II receptor blocker (ARB) $(4.58 \pm 0.013 \mathrm{mEq} / \mathrm{L})$ and the group prescribed angiotensinconverting enzyme inhibitor (ACEI) $(4.59 \pm 0.021 \mathrm{mEq} / \mathrm{L})$. The relationship between serum potassium level and RAS inhibitor use in patients stratified by eGFR was analyzed. As shown in Fig. 5, serum potassium level was elevated by approximately $0.1 \mathrm{mEq} / \mathrm{L}$ in each eGFR subgroup.
Multiple regression analysis was conducted to elucidate the relationship between serum potassium level and several factors. A significant correlation was obtained for six factors (Table 2). The strongest correlation (inversed) was observed with reduced eGFR, followed by diabetic status, male gender, old age, ARB prescription and ACEI prescription, in descending order of correlation. These results were almost the same as those of our previous study (8), with the exception that the male gender was a significant factor in the present 

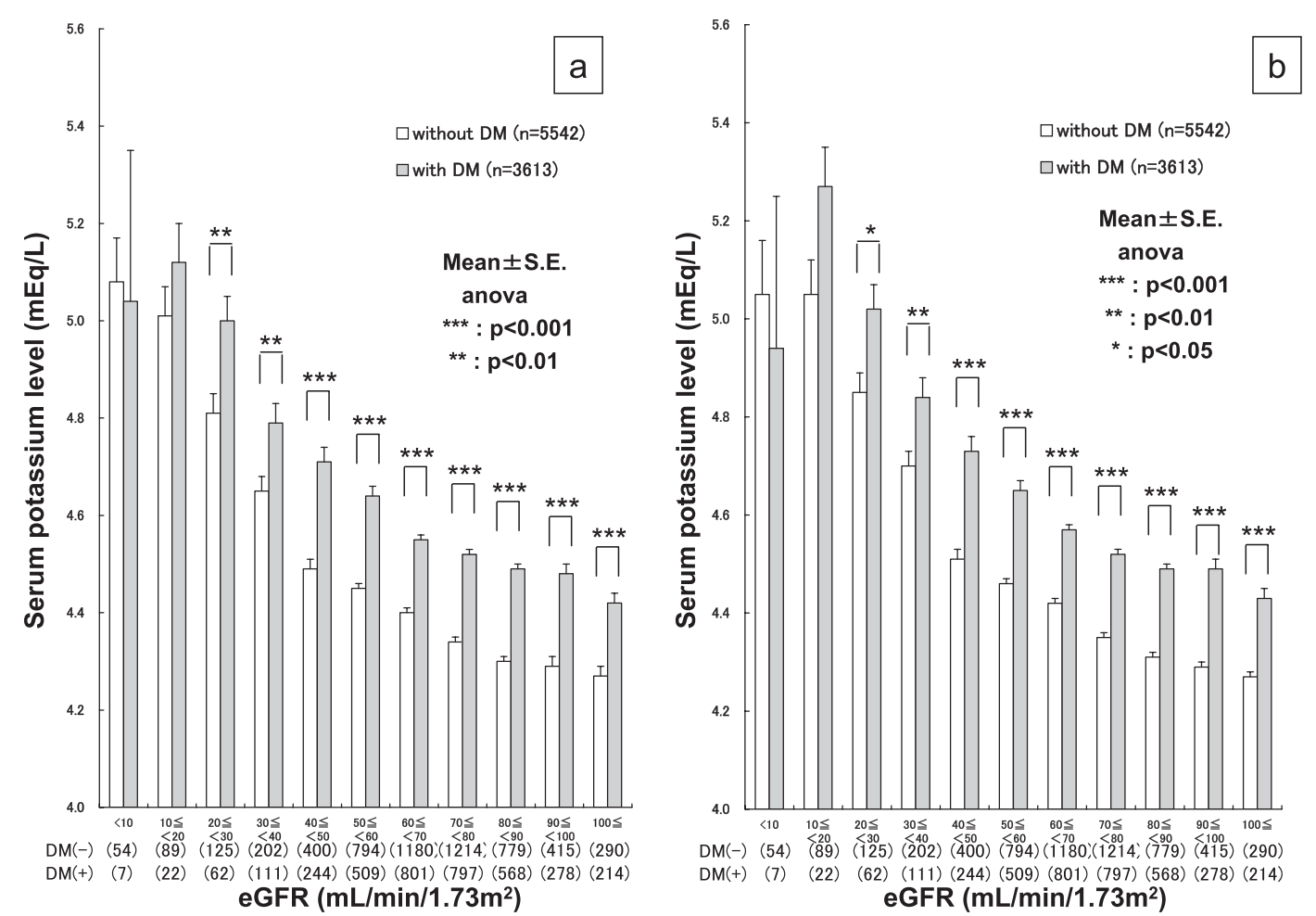

Figure 4. Serum potassium level stratified by estimated glomerular filtration rate (eGFR) in diabetic and non-diabetic patients. a: eGFR was calculated using equation 0.741. b: eGFR was calculated using equation 194. The number of the patients in each group is shown in parentheses.
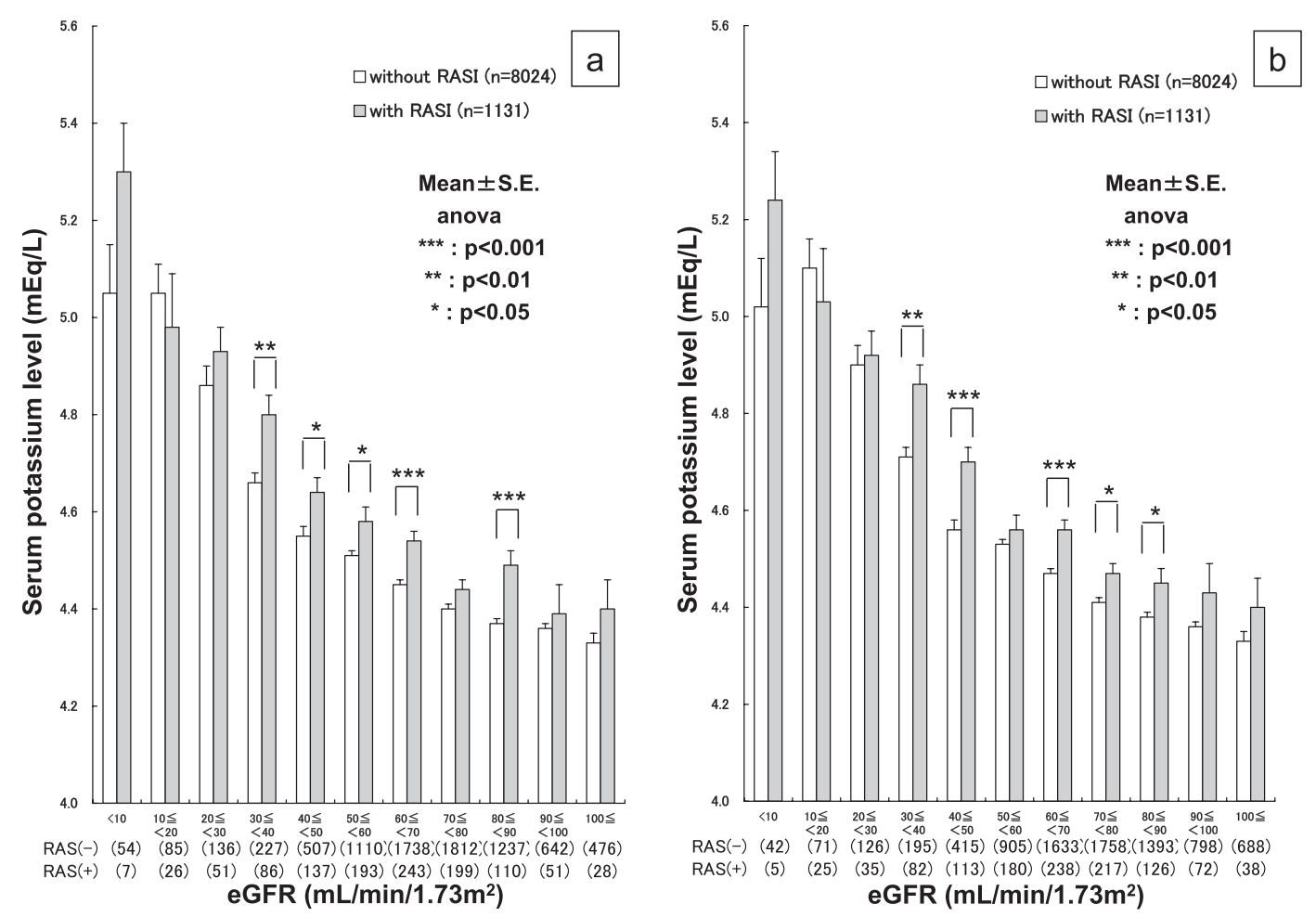

Figure 5. Serum potassium level stratified by estimated glomerular filtration rate (eGFR) in patients with and without renin-angiotensin system inhibitor (RASI) prescription. a: eGFR was calculated using equation 0.741 . b: eGFR was calculated using equation 194. The number of the patients in each group is shown in parentheses.

multiple regression study but it was not in the previous study.
To examine the level of eGFR that significantly affect the incidence of hyperkalemia, the incidence of hyperkalemia in 
Table 2. Multiple Regression Analysis

equation 0.741

\begin{tabular}{llll}
\hline Variable & $\begin{array}{l}\text { Partial regression } \\
\text { coefficient }\end{array}$ & $\begin{array}{l}\text { Standard partial } \\
\text { regression coefficient }\end{array}$ & $\mathrm{p}$ value \\
\hline Estimated GFR & -0.00496338 & -0.27868 & $<0.001$ \\
Diabetes & 0.143633 & 0.190341 & $<0.001$ \\
Gender & -0.0574497 & -0.0769439 & $<0.001$ \\
Age & 0.00188783 & 0.0709001 & $<0.001$ \\
ARB administration & 0.0498826 & 0.038916 & $<0.001$ \\
ACEI administration & 0.0567775 & 0.0297596 & $<0.01$ \\
\hline
\end{tabular}

Stepwise forward selection method: $\geqq \mathrm{F}$ in $=2, \quad<\mathrm{F}$ out $=2$

Multiple coefficient of determination: $\mathrm{R}^{2}=0.15867$

Multiple correlation coefficient $: \mathrm{R}=0.398334$

\begin{tabular}{llll} 
equation 194 & & \\
\hline parameter & $\begin{array}{l}\text { partial regression } \\
\text { coefficient }\end{array}$ & $\begin{array}{l}\text { standard partial } \\
\text { regression coefficient }\end{array}$ & p value \\
\hline Estimated GFR & -0.00495529 & -0.287408 & $<0.001$ \\
Diabetes & 0.143329 & 0.189937 & $<0.001$ \\
Gender & -0.0643596 & -0.0861986 & $<0.001$ \\
Age & 0.00122577 & 0.0460354 & $<0.001$ \\
ARB administration & 0.0494948 & 0.0386135 & $<0.001$ \\
ACEI administration & 0.056186 & 0.0294495 & $<0.01$ \\
\hline
\end{tabular}

stepwise forward selection method: $\geqq$ Fin $=2 \quad, \quad<$ Fout $=2$

multiple coefficient of determination $\quad \mathrm{R}^{2}=0.158471$

multiple correlation coefficient $\quad \mathrm{R}=0.398084$

GFR : glomerular filtration rate, ACEI: angiotensin-converting-enzyme inhibitors, ARB: angiotensin-II receptor blockers.

patients stratified by eGFR was studied. As shown in Fig. 6, the reduction of eGFR was associated with a definite increase in incidence of hyperkalemia.

Multiple comparison was conducted to analyze the difference in the incidence of hyperkalemia between the eGFR subgroups. The result using equation 0.741 is shown in Fig. 6a. The subgroup with eGFR 40 or above but below 50 $\mathrm{mL} / \mathrm{min} / 1.73 \mathrm{~m}^{2}$ had a significantly higher incidence than each of the eGFR subgroups above eGFR $60 \mathrm{~mL} / \mathrm{min} / 1.73$ $\mathrm{m}^{2}$. When this analysis was repeated for each of the subgroups, a significantly higher incidence of hyperkalemia was observed when each of the subgroup with eGFR below 50 $\mathrm{mL} / \mathrm{min} / 1.73 \mathrm{~m}^{2}$ was compared with all the subgroups with higher eGFR. Almost no significant differences in incidence of hyperkalemia were observed when each of the subgroups with eGFR $50 \mathrm{~mL} / \mathrm{min} / 1.73 \mathrm{~m}^{2}$ or above was compared with the subgroups with higher eGFR. Therefore, from the viewpoint of increase in incidence of hyperkalemia, it is important to set the cutoff at eGFR below $50 \mathrm{~mL} / \mathrm{min} / 1.73 \mathrm{~m}^{2}$, when equation 0.741 is used to estimate GFR.

When the same analysis was performed using eGFR calculated with equation 194, eGFR below $60 \mathrm{~mL} / \mathrm{min} / 1.73 \mathrm{~m}^{2}$ had significantly higher incidence of hyperkalemia com- pared with almost all the subgroups with higher eGFR as shown in Fig. 6b.

Next we compared the incidence of hyperkalemia in diabetic patients and non-diabetic patients. As shown in Table 3 , the incidence of hyperkalemia in diabetic patients was higher than that in non-diabetic patients in many subgroups of stratified eGFR.

\section{Discussion}

The number of patients with ESRD in Japan has shown a continuous increase for the past years (2). The same trend is also observed globally. The number of ESRD is predicted to increase from 410,000 in 1990 to $2,100,000$ in 2010 , or a five-fold increase in twenty years (1).

Go et al (3) showed a correlation between reduced renal function and risk of cardiovascular disease. Compared to patients with eGFR $60 \mathrm{~mL} / \mathrm{min} / 1.73 \mathrm{~m}^{2}$ or above, the adjusted hazard ratio for cardiovascular events increased from 1.4 with an eGFR of 45 to $59 \mathrm{ml} / \mathrm{min} / 1.73 \mathrm{~m}^{2}$ to 2.0 with an eGFR of 30 to $44 \mathrm{ml} / \mathrm{min} / 1.73 \mathrm{~m}^{2}, 2.8$ with an eGFR of 15 to $29 \mathrm{ml} / \mathrm{min} / 1.73 \mathrm{~m}^{2}$, and 3.4 with an eGFR of less than 15 $\mathrm{ml} / \mathrm{min} / 1.73 \mathrm{~m}^{2}$. Furthermore, the hazard ratios for death 

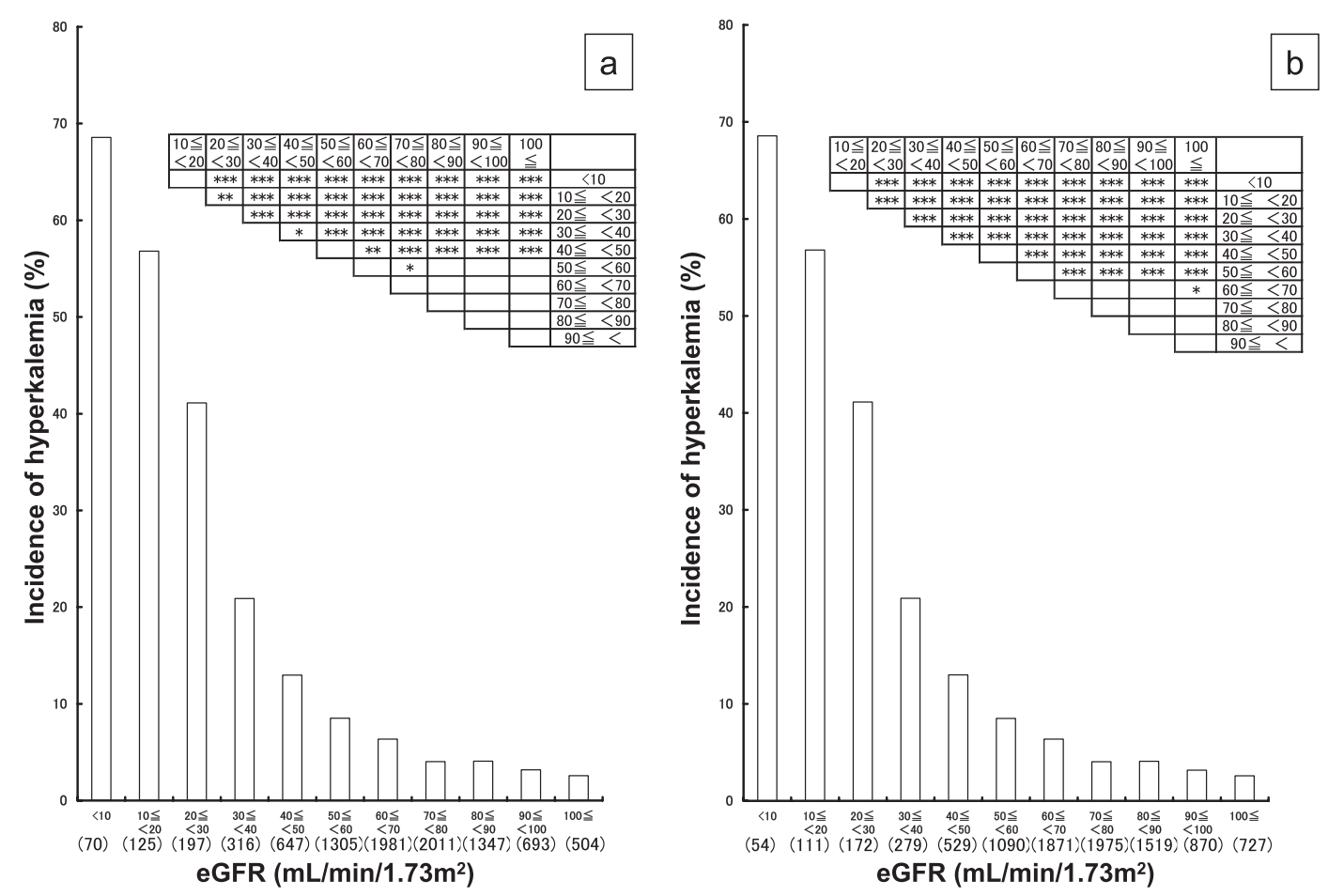

Figure 6. Incidence of hyperkalemia in patients stratified by estimated glomerular filtration rate (eGFR). a: eGFR was calculated using equation 0.741. b: eGFR was calculated using equation 194. The number of the patients in each group is shown in parentheses.

Table 3. The Incidence of Hyperkalemia in Patients with or without DM

\begin{tabular}{lcccccccccccc} 
eqfR & $<10$ & $\begin{array}{r}10 \leqq \\
<20\end{array}$ & $\begin{array}{r}20 \leqq \\
<30\end{array}$ & $\begin{array}{r}30 \leqq \\
<40\end{array}$ & $\begin{array}{r}40 \leqq \\
<50\end{array}$ & $\begin{array}{r}50 \leqq \\
<60\end{array}$ & $\begin{array}{r}60 \leqq \\
<70\end{array}$ & $\begin{array}{r}70 \leqq \\
<80\end{array}$ & $\begin{array}{c}80 \leqq \\
<90\end{array}$ & $\begin{array}{c}90 \leqq \\
<100\end{array}$ & $100 \leqq$ & total \\
\hline non-DM & 67.7 & 53.0 & 34.6 & 14.3 & 7.8 & 4.5 & 4.2 & 2.1 & 2.6 & 2.2 & 1.7 & 6.2 \\
DM & 62.5 & 64.0 & 46.3 & 32.7 & 21.1 & 14.7 & 9.6 & 6.9 & 6.2 & 4.7 & 3.7 & 11.1 \\
\hline p & ns & ns & ns & $<0.001$ & $<0.001$ & $<0.001$ & $<0.001$ & $<0.001$ & $<0.01$ & ns & ns & $<0.001$
\end{tabular}

\begin{tabular}{|c|c|c|c|c|c|c|c|c|c|c|c|c|}
\hline \multirow{2}{*}{ eGFR } & \multirow{2}{*}{$<10$} & $10 \leqq$ & $20 \leqq$ & $30 \leqq$ & $40 \leqq$ & $50 \leqq$ & $60 \leqq$ & $70 \leqq$ & $80 \leqq$ & $90 \leqq$ & \multirow{2}{*}{$100 \leqq$} & \multirow{2}{*}{ total } \\
\hline & & $<20$ & $<30$ & $<40$ & $<50$ & $<60$ & $<70$ & $<80$ & $<90$ & $<100$ & & \\
\hline non-DM & 63.8 & 58.1 & 38.8 & 20.7 & 8.2 & 5.3 & 4.2 & 2.6 & 2.3 & 2.3 & 1.8 & 6.2 \\
\hline $\mathrm{DM}$ & 57.1 & 83.3 & 48.2 & 34.3 & 23.0 & 17.0 & 10.2 & 7.2 & 6.0 & 5.6 & 3.9 & 11.1 \\
\hline $\mathrm{p}$ & $\mathrm{ns}$ & $\mathrm{ns}$ & $\mathrm{ns}$ & $<0.05$ & $<0.001$ & $<0.001$ & $<0.001$ & $<0.001$ & $<0.001$ & $<0.05$ & $\mathrm{~ns}$ & $<0.001$ \\
\hline
\end{tabular}

were $1.2,1.8,3.2$ and 5.9, respectively, compared to patients with eGFR $60 \mathrm{~mL} / \mathrm{min} / 1.73 \mathrm{~m}^{2}$ or above, showing even higher ratios than the risk for cardiovascular disease. These findings indicate that reduced renal function has a great impact on the cardiovascular system, and the risk is amplified by interacting with reduced renal function, posing great risk on the life of patients. These findings were also demonstrated in the follow-up study of the United Kingdom Prospective Diabetes Study (UKPDS), a large-scale study on type 2 diabetic patients. In that report, the annual all-cause death rates were $1.4 \%$ at the stage of no nephropathy, $3.0 \%$ at the microalbuminuria stage, $4.6 \%$ at the overt nephropathy stage, and $19.2 \%$ at the stage of elevated plasma creatinine or ESRD (9). Over half of the deaths were cardiovascular deaths.

With the recognition that reduced renal function has great impact on patient outcome, the CKD concept has been introduced and early treatment for patients with reduced renal function has been promoted. Measurement of GFR is necessary for accurate assessment of renal function. Since GFR 
measurement is too complicated for the routine clinical setting, GFR is usually estimated by the MDRD equation using serum creatinine level, age and gender. Although it is known that eGFR and measured GFR show racial differences, an equation for estimating GFR in Japanese had not been available. In 2007, the Japanese Society of Nephrology published the equation for GFR estimation based on Japanese data (6). The Japanese Society of Nephrology also introduced another equation to estimate GFR in the annual meeting in 2007. Thus, we used these two equations to evaluate renal function in Japanese in this paper.

The distribution of eGFR in Japanese is known to be at a lower level than that in the US population. When the commonly used criterion of eGFR lower than $60 \mathrm{~mL} / \mathrm{min} / 1.73$ $\mathrm{m}^{2}$ is used to define CKD stage 3 or above, the proportion of patients is $4.5 \%$ in the US and $18.7 \%$ in Japan, showing a more than four-fold increase in number of patients in Japan (7). On the other hand, the proportion of Japanese patients with eGFR lower than $50 \mathrm{~mL} / \mathrm{min} / 1.73 \mathrm{~m}^{2}$ is only approximately $4 \%$. This observation implies the possibility that the clinically significant level of eGFR is lower than $50 \mathrm{~mL} /$ $\min / 1.73 \mathrm{~m}^{2}$, but does not explain what significance this has related to the actual disease condition.

Serum potassium level is strictly controlled at a narrow range of 3.5 to $5.0 \mathrm{Eq} / \mathrm{L}$, which is irrespective of the variation in amount of potassium consumption from food. Hyperkalemia causes fatal arrhythmia. Approximately $90 \%$ of potassium is excreted via the kidney. Since serum potassium level is easily affected by reduced renal function, hyperkalemia is a very important complication when renal function is deteriorated. The purpose of the present study was to define the level of renal function that influences the onset of hyperkalemia. We found a significant increase in incidence of hyperkalemia at eGFR $50 \mathrm{~mL} / \mathrm{min} / 1.73 \mathrm{~m}^{2}$ rather than eGFR below $60 \mathrm{~mL} / \mathrm{min} / 1.73 \mathrm{~m}^{2}$ when equation 0.741 was used to estimate GFR, indicating that from the viewpoint of the incidence of hyperkalemia, it is more reasonable to adopt an eGFR lower than $50 \mathrm{~mL} / \mathrm{min} / 1.73 \mathrm{~m}^{2}$ as the clinically significant cutoff, rather than an eGFR lower than 60 $\mathrm{mL} / \mathrm{min} / 1.73 \mathrm{~m}^{2}$. Thus, it might be reasonable that Japanese Society of Nephrology recommends the referral of the patients with eGFR less than $50 \mathrm{~mL} / \mathrm{min} / 1.73 \mathrm{~m}^{2}$ to the nephrologists in clinical practice guidelines (6), where the use of equation 0.741 is recommended to calculate eGFR.
The confirmation of the validity of equation 194 is now in process. The equation194 might be used in the future. Estimated GFR calculated with equation 194 tended to be higher than that calculated with equation 0.741 . Our results showed that eGFR less than $60 \mathrm{~mL} / \mathrm{min} / 1.73 \mathrm{~m}^{2}$ was significant for Japanese from the viewpoint of increased incidence of hyperkalemia when equation 194 was used to calculate GFR.

Since diabetes was a significant risk factor of hyperkalemia and the incidence of hyperkalemia in diabetic patients was higher than that in non-diabetic patients in many subgroups of stratified eGFR, it is important to be careful to watch for hyperkalemia in diabetic patients even though eGFR is not reduced.

In a previous study in which we used serum creatinine level as the indicator of renal function, we demonstrated that elevated serum creatinine level, diabetes, use of RAS inhibitors and old age significantly increased the serum potassium level (8). In the present study, we re-evaluated renal function using eGFR as the indicator and performed the same analysis. The present analysis showed that reduced eGFR, diabetes, use of RAS inhibitors and old age significantly increased the serum potassium level, similar to the previous study using serum creatinine as indicator. In the previous study using serum creatinine, the male gender was found to be a significant factor associated with increase in serum potassium level in univariate analysis, but this variable became insignificant in multivariate analysis. However, in the present analysis using eGFR, gender also remains a significant factor for the increase in serum potassium level in multivariate analysis. Therefore male gender should be considered to be a significant factor for the elevation of serum potassium level.

In summary, the present analysis in which eGFR calculated from the equations for Japanese was used to assess renal function, reduced eGFR, diabetes, male gender, old age and use of RAS inhibitors were found to be factors associated with an elevated serum potassium level. From the viewpoint of the increase in incidence of hyperkalemia, using an eGFR below $50 \mathrm{~mL} / \mathrm{min} / 1.73 \mathrm{~m}^{2}$ as the cutoff has greater clinical significance than an eGFR below $60 \mathrm{~mL} / \mathrm{min} / 1.73$ $\mathrm{m}^{2}$ when equation 0.741 is used and the cutoff at $60 \mathrm{~mL} /$ $\min / 1.73 \mathrm{~m}^{2}$ is appropriate when equation 194 is used.

\section{References}

1. Lysaght MJ. Maintenance dialysis population dynamics: current trends and long-term implications. J Am Soc Nephrol 13(Suppl 1): S37-S40, 2002.

2. Statistical Study Committee of Japanese Society of Dialysis Therapy: Status of chronic dialysis therapy in Japan as of December 31, 2006. Japanese Society of Dialysis Therapy, Tokyo, 2006 (in Japanese).

3. Go AS, Chertow GM, Fan D, McCulloch CE, Hsu CY. Chronic kidney disease and the risks of death, cardiovascular events, and hospitalization. N Engl J Med 35: 1296-1305, 2004.
4. Ninomiya T, Kiyohara Y, Kubo M, et al. Chronic kidney disease and cardiovascular disease in a general Japanese population: the Hisayama Study. Kidney Int 68: 228-236, 2005.

5. Sarnak MJ, Levey AS, Schoolwerth AC, et al. Kidney disease as a risk factor for development of cardiovascular disease: a statement from the American Heart Association Councils on Kidney in Cardiovascular Disease, High Blood Pressure Research, Clinical Cardiology, and Epidemiology and Prevention. Circulation 108: 21542169, 2003.

6. Japanese Society of Nephrology. Clinical practice guidelines for 
diagnosis and treatment of chronic kidney disease. Jpn J Nephrol 49: 755-870, 2007 (in Japanese).

7. Imai E, Horio M, Iseki K, et al. Prevalence of chronic kidney disease (CKD) in the Japanese general population predicted by the MDRD equation modified by a Japanese coefficient. Clin Exp Nephrol 11: 156-163, 2007.
8. Takaichi K, Takemoto F, Ubara Y, Mori Y. Analysis of factors causing hyperkalemia. Intern Med 46: 823-829, 2007.

9. Adler AI, Stevens RJ, Manley SE, Bilous RW, Cull CA, Holman RR; UKPDS GROUP. Development and progression of nephropathy in type 2 diabetes: the United Kingdom Prospective Diabetes Study (UKPDS 64). Kidney Int 63: 225-232, 2003.

(C) 2008 The Japanese Society of Internal Medicine http://www.naika.or.jp/imindex.html 